NASA Technical Memorandum 85712

\title{
A Flight Test of Laminar Flow Control Leading-Edge Systems
}

M.C. Fischer, A.S. Wright,Jr., and R.D. Wagner

DECEMBER 1983

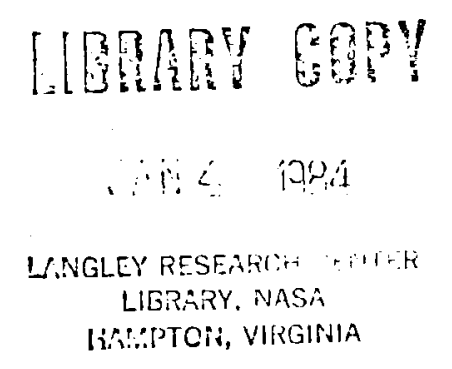




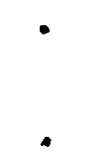




\title{
A FLIGHT TEST OF LAMINAR FLOW CONTROL LEADING-EDGE SYSTEMS
}

\author{
M. C. Fischer, A. S. Wright, Jr., and R. D. Wagner \\ NASA Langley Research Center \\ Hampton, Virginia
}

\section{Abstract}

NASA's program for development of a laminar flow technology base for application to commercial transports has made significant progress since its inception in 1976. Current efforts are focused on development of practical reliable systems for the leading-edge region where the most difficult problems in applying laminar flow exist. Practical solutions to these problems will remove many concerns about the ultimate practicality of laminar flow. To address these issues, two contractors performed studies, conducted development tests, and designed and fabricated fully functional leadingedge test articles for installation on the NASA JetStar aircraft. Systems evaluation and performance testing will be conducted to thoroughly evaluate all system capabilities and characteristics. A simulated airline service flight test program will be performed to obtain the operational sensitivity, maintenance, and reliability data needed to establish that practical solutions exist for the difficult leading-edge area of a future commercial transport employing laminar flow control.

\section{Nomenclature}

$\begin{array}{ll}\text { ACEE } & \text { Aircraft Energy Efficiency } \\ c & \text { chord, ft } \\ C_{L} & \text { lift coefficient } \\ C P & \text { surface pressure coefficient } \\ C_{q} & \text { suction coefficient } \\ \text { DFRF } & \text { Dryden Flight Research Facility } \\ \text { EBP } & \text { electron beam perforated } \\ \text { HLFC } & \text { hybrid laminar flow control } \\ \text { LEFT } & \text { leading-Edge Flight Test } \\ \text { LFC } & \text { laminar flow control } \\ M & \text { free-stream Mach number } \\ n & \text { logarithmic exponent of integrated dis- } \\ & \text { turbance amplitude ratio } \\ \text { NLF } & \text { natural laminar flow } \\ \text { PGME } & \text { propylene glycol methyl ether } \\ R_{C} & \text { Reynolds number based on chord } \\ x / c & \text { nondimensional distance along wing in } \\ & \text { streamwise direction }\end{array}$

\section{Introduction}

Laminar flow is a technology with great potential for drag reduction and, hence, fuel savings. The concept dates back to the 1930's and 1940's, the beginnings of modern stability theory for laminar boundary layers. In that period stability analysis methods were developed by Tollmien ${ }^{1}$ and Schlichting ${ }^{2}$ and confirmed by the experiments of Schubauer and Skramstad. ${ }^{3}$ Early applications of the theory led to the observations that laminar boundary layers can be stabilized by either favorable pressure gradients or small amounts of wall suction.
Extensive research was performed in many countries to explore each of these approaches. Stabilization by pressure gradient became known as natural laminar flow (NLF), and NACA research in this area led to the development of the 6-series natural laminar flow airfoils. International research on stabilization by suction, referred to as laminar flow control ( $L F C$ ), was intensive at the same time and culminated in the United States with the flight tests of an unswept suction glove on an F-94 aircraft $^{4}$ and the $X-21$ flight tests $5,6,7,8$ of a totally new swept LFC wing on a reconfigured WB-66 aircraft
in the 1960 's. These flight experiments removed any doubt that extensive laminar flow could be achieved in flight. However, after the flight tests unresolved concerns remained related to the practicality of producing (with technology then available) wings sufficiently smooth and wavefree, and maintaining the wing surface quality in normal service operations.

In 1976 NASA initiated efforts in laminar boundary-layer control for drag reduction as a part of the Aircraft Energy Efficiency (ACEE) Program to develop new technology for fuel efficient commercial transports. Significant progress has been made exploiting new materials and fabrication techniques, analys is methods, and design concepts to develop the technology and provide convincing evidence that practical, reliable, maintainable systems for future transport aircraft could become a reality.

The most difficult problems of achieving laminar flow on commercial transports appear to be associated with the leading-edge region. The leading edge is subjected to foreign object damage, insect impingement, rain erosion, icing, and other contaminants. Practical, durable leading-edge structure is required which contains a suction system, cleaning system, and an anti-icing system. Most of these problems are common to all the concepts for achieving extensive laminar flow, and practical solutions to these problems will remove many concerns about the ultimate practicality of laminar flow.

\section{Leading-Edge Flight Test Program}

The Leading-Edge Flight Test (LEFT) is one element of the ACEE program effort to develop laminar flow technology. 10 In the LEFT, flight evaluations will be performed to determine the effectiveness of laminar flow leading-edge systems developed over the past few years. Critical data to demonstrate operational reliability and maintainability will be obtained. Operable leading-edge systems, including suction, surface insect/contamination protection, and anti-icing systems, are being installed in the leading edge of the NASA DFRF JetStar aircraft (Fig. 1). Both the Douglas Aircraft Company and the Lockheed-Georgia Company have designed and fabricated a leading-edge test article to demonstrate that the required systems can be packaged 
into a leading-edge section representative of future LFC commercial transport aircraft, and that these systems can operate reliably with acceptable maintenance requirements in an airline flight environment. The Douglas leading-edge test article and the Lockheed leading-edge test article are fundamentally different in their design. The designs have evolved as a result of extensive design studies and development testing performed under NASA LFC system studies contracts 11,12 as well as the present contracts. These efforts focused on addressing special concerns associated with systems and structures, such as development of leading-edge insect/ anti-icing protection systems and development of practical, reliable structures which meet the external smoothness and waviness requirements. In these studies, structural specimens were designed, fabricated, and successfully tested to demonstrate their effectiveness and durability against lightning strikes, corrosion, rain erosion, extreme moisture and temperature conditions, and foreign object damage. Structural specimens were subjected to extensive compression, tension, fatigue, and bending tests. Repair techniques were also developed. These studies demonstrated that structures which meet the laminar flow smoothness and waviness tolerance criteria can be manufactured without excessive costs or unacceptable structural weight penalties.

A principal concern in the leading-edge region is residue from insect impacts on the wing which can produce surface roughness of sufficient levels to prevent attainment of laminar flow during cruise at altitudes and speeds of subsonic transport operations. To provide preliminary answers as to the degree of the insect contamination problem for airline service, and to evaluate the effectiveness of superslick, or hydrophobic, surface coatings and a liquid spray washing system for preventing or minimizing insect contamination, NASA conducted a flight test program early in the LFC program with the NASA DFRF JetStar aircraft. ${ }^{13}$ An outboard wing leadingedge test panel, with four chordwise strips of different surface coatings (Fig. 2), was equipped with total head tubes on the upper surface to detect transition in the leading edge and with a series of water spray nozzles on the lower surface for coating the upper and lower surfaces with a protective fluid film. Airline-type flights conducted in and out of major airports across the United States (with no protective spray) indicated that insects can contaminate the wing leading edge to prevent achieving laminar flow. The surface coatings (Tefion tape and spray-on, organo-silicone, and radome rain repellant) were not effective in preventing the contamination. These limited flight samples (15 airline-type flights) are not all-inclusive and the degree of severity of contamination will be seasonal and depend on geographical location. 11 Flight tests were then conducted in agricultural areas heavily populated with insects which illustrated that injection of a water spray to maintain a wet surface while encountering insects is effective in preventing insect contamination of the leading edge. The results from these preliminary flight tests indicated that, until extensive flight testing could be performed to assess the operational requirements for insect protection, a prudent course for the laminar flow program would be to develop an effective anti-contamination system. In the LEFT contracts, 14,15 which culminated in the hardware delivery of two functional test articles, design and fabrication development effort was focused on practical, representative leading-edge structures and systems for installation on the NASA DFRF JetStar. This effort involved in-depth materials, structural component and panel testing, and wind tunnel testing. The following highlights the effort performed in this area.

\section{Lockheed Concept Development and Testing}

For the leading-edge flight test, Lockheed's approach (Fig. 3) involves suction through fine spanwise slots ( 0.004 inch width) on both the upper and lower surfaces to the front spar. No leadingedge high-lift device is required with the Lockheed concept. A 0.016 inch thick titanium outer sheet is bonded to a sandwich substructure of graphite epoxy face sheets with a Nomex honeycomb core. The suction flow is routed through the structure by a combination of slot ducts, metering holes and collector ducts embedded in the honeycomb. To enhance the research value of the flight tests and enable system optimization, the test article is designed with individual control of the suction flow through each slot so that the suction distributions can be varied. Only a passive system would be required on an operational transport, i.e., individual slot flow control would not be necessary. Six slots in the leading edge serve the dual purpose of providing a protective fluid film for both insect protection and anti-icing. These slots are purged of fluid during climbout and join the other suction slots for laminarizing the boundary layer in cruise.

As noted in Figure 3, Lockheed's concept for protecting the leading-edge region from insect contamination, as well as providing anti-icing protection, consists of injecting cleaning/anti-icing fluid through slots above and below the attachment line. Lockheed verified the feasibility of this concept during wind tunnel tests in their low speed wind tunnel facility. 11 A partial span full-scale leading-edge section (Fig. 4) was subjected to insects injected in the free stream at number densities much higher than expected in actual flight at takeoff or landing conditions. Takeoff and climbout speeds up to 154 knots and angles of attack up to $15^{\circ}$ were simulated. Cleaning fluid injected through leading-edge slots provided a protective fluid film which protected the upper and lower surfaces from insect residue accretion. The dual purpose (suction/cleaning) operation of the slots in the leading edge was also evaluated during these tests, which established their feasibility but illustrated the need for proper valving and leak tight sealing.

Fabrication of the test articles, in particular bonding of the titanium skin and forming the composite sandwich substructure, involved consideration of several factors peculiar to this application. Bonding temperatures and autoclave curing temperatures were held to lower levels than normally encountered because of the desire to avoid expensive high temperature tooling. The lower curing and bonding temperatures are desirable also to avoid part distortion and locking-in of thermal stresses that can produce surface distortion and waviness in the structure which exceeds the laminar flow waviness criteria. An additional concern is the degradation of the selected adhesive after exposure to the cleaning/anti-icing fluid, which consists of $60 \%$ propylene glycol methyl ether (PGME) and $40 \%$ water. Several candidate adhesives were used to bond titanium sheet to graphite epoxy structure at 
varying temperatures to determine which provided an acceptable shear stress. The adhesive which exhibited the most acceptable characteristics was selected. To resolve the issue of strength degration after exposure to PGME, 20 structural titanium/composite specimens bonded with the selected adhesive were immersed for several weeks in a 60/40 PGME solution. The lap shear stress measured after immersion exceeded the design allowable by a high margin of safety.

Panel verification tests were performed to verify the structural integrity of the leadind-edge panel in spanwise bending, chordwise bending, shear, compression, and flatwise tension. Three groups of panel verification specimens were tested, including column compression, four point bending, and flatwise tension. The specimens were exposed to stress levels beyond the specification requirements thus verifying the design.

Much effort was concentrated on improved methods for cutting and measuring the width of slots in titanium, and for fabricating smooth, wave free, close tolerance leading-edge structure. Problems incurred during slot cutting in the past involved slot saw blade breakage and slow cutting speeds. 11 These tests showed that effective application of titanium cutting coolants reduces breakage and permits a slot to be cut with acceptable speed and width uniformities. Lockheed experienced some difficulties throughout the manufacturing development phase regarding the fabrication of their structure to the leading-edge contour with all the slot duct inserts, collector ducts, and inner/outer face sheets which had to be maintained in close alignment during numerous autoclave entries. A 2-foot span section representative of the leading edge was fabricated to improve techniques, such as establishing cure cycles and temperatures, layup processes, and plumbing installation. Development testing verified that the titanium skin had to be hot formed to prevent springback and subsequent closing of the slots after cutting. A low cost hot forming process suggested by NASA was ultimately utilized by Lockheed to stress relieve the titanium skin.

Lockheed performed several structural tests using full size leading-edge specimens to verify the structural integrity of the test article design and the flight hardware.

\section{Douglas Concept Development and Testing}

The Douglas concept 15,16 selected for testing on the leading-edge flight test employs electron beam perforated (EBP) titanium sheet bonded to a fiberglass corrugated substructure. This concept (Fig. 5) is a porous strip approach with about $60 \%$ of the surface porous and about $40 \%$ blocked where the skin bonds to the land area of the corrugated substructure. The 15 active flutes are used for subsurface air collection with individual control for varying the suction in each. The inactive or spacer flutes contain the surface instrumentation. The EBP titanium skin is 0.025 inch thick with perforated holes that are 0.0025 inch in diameter at the suction surface and taper to about twice that diameter at the inside surface (Fig. 5). Hole spacing is about 0.030 inch between centers. Suction is applied only on the upper surface, from just below the attachment line to the front spar. Douglas studies indicated the upper surface suction concept to be most cost effective because of reduced maintenance requirements, less weight and initial cost, and elimination of lower surface suction systems and the stringent smoothness requirements permits the use of a Krueger high lift device. The Krueger is designed to be an effective insect shield but is configured such as not to produce high ifft increases at low speeds for these tests because of aircraft asymmetry and safety concerns. A spray nozzle system is mounted on the Krueger underside to supplement the shield in providing insect protection and to coat the leading edge with anti-icing fluid to prevent icing. The shield leading edge is equipped with a commercially available ice protection system manufactured by TKS, Ltd. A system for purging fluid from the suction flutes and surface perforations is provided if required. An interesting feature about the DAC concept is that the suction panel is removable from the rest of the rib supporting substructure so that other panel concepts could be tested with minimum effort. Also, there is relatively easy access to the leading-edge systems and instrumentation for inspection and repair if required by deploying the Krueger on the ground and removing access panels.

As a result of trade studies and development testing, Douglas elected to utilize the Krueger high lift device as a protective shield against insect impact. Tests were conducted 12 in the NASA Lewis Icing Research Tunnel (Fig. 6) to evaluate the effectiveness of a Krueger shield in protecting the leading edge from insect contamination. Insects of representative sizes and number density were injected into the tunnel free stream ahead of the model. These tests (supported by trajectory analysis) demonstrated that the Krueger serves as an effective line-of-sight shield for heavy insects, but suggest that a supplemental spray may be necessary to protect against possible impingement of lighter insects in some areas of the wing. For this reason, the supplemental spray nozzle system was mounted on the Krueger underside as pointed out in the discussion of Figure 5.

Since there were limited wind tunnel data available regarding laminarization of boundary layers with perforated surfaces, and because the hole sizes and spaces with the EBP sheet were much smaller than surfaces previously utilized, DAC conducted a wind tunnel test in their low speed tunnel 15,16 with a swept 2-D airfoil (Fig. 7) to verify that suction through the perforated surface is effective in laminarizing the boundary layer flow. The 7-foot chord, $30^{8}$ sweep model was designed to produce an upper surface pressure distribution typical of that expected on the Jetstar. The tunnel sidewalls were contoured to produce the infinite swept airfoil pressure distribution. The test results verified the increased effectiveness of applying suction at and just behind the attachment line, and showed that perforated strip suction is tolerant of surface anomalies like nonuniform porosity, spar joints, and weld seams. Spanwise pressure gradients were induced by proper deflection of three trailing-edge flaps and laminar flow was maintained by a slight increase in suction level. The tunnel conditions $\left(M_{\infty}=0.2, R_{\infty} / f t=1.35\right)$ are less severe than the fight conditions $\left(M_{\infty}=0.75\right.$, $\left.R_{\infty} / f t=1.65\right)$ but the favorable results serve to provide increased confidence in the use of perforated surfaces. This wind tunnel test also served 
to evaluate and refine the internal airflow design, the metering system, and the suction plumbing system.

DAC performed tests to ensure that the adhesive selected for bonding the titanium skin to the fiberglass substructure would maintain adequate strength in the presence of PGME and elevated operational temperatures. Physical properties for the low curing temperature of the fiberglass epoxy material were not available and were determined from tests conducted under operational environmental conditions of moisture and temperature. Wet and dry tests over various temperature conditions were conducted to determine primarily the strength of the resin between fiberglass layers (interlaminar shear) and the bond of titanium skin to fiberglass substructure (double-lap shear). Other properties measured included tension, compression, rail shear, fastener shear-out, fastener bearing, and climbingdrum peel strength. DAC fabricated specimens which were representative of the leading-edge test article structure and conducted tests to demonstrate the suitability of the structural design.

\section{Aerodynamic Design and Suction Requirements}

The test articles are being installed in a midspan segment of the JetStar leading edge created by removal of the wing slipper tanks (Fig. 8). The span length of the test articles is 61.25 inches ( $20 \%$ of span) and the leading-edge sweep is $30^{\circ}$. Chord Reynolds number at the design condition is about 16 million. The chordwise extent of the test articles is to the Jetstar front spar (Figs. 8 and 9), where fiberglass fairings continue the glove aerodynamic contour to the rear spar $(65 \% \mathrm{x} / \mathrm{c})$ on the upper surface and just beyond the front spar on the lower surface. The aerodynamic contours formed on each wing by the test articles and fiberglass fairings are identical. Within the geometric confines described above, the aerodynamic contour was tailored to produce a representative advanced supercritical pressure distribution over the forward portion of the gloved region at design conditions of $M=0.75$ and $38,000 \mathrm{ft}$ (Fig. 9). Advanced airfoil and wing design methods were employed to determine the contour and pressure distribution. A design goal was to attain pressure isobars on the test surface parallel to the leading edge to avoid or minimize spanwise pressure gradients along the suction slots or porous strips. Also, the nose shape was designed to allow an initial rapid flow expansion, i.e., steep favorable pressure gradient (Fig. 9) to help control the growth of crossflow boundary-layer disturbances and minimize suction requirements.

The aerodynamic design effort was made particularly difficult because of the less rapid pressure expansion which occurs on the basic Jetstar wing, the limited span of the test articles, and the influence of the aft mounted engines on the pressure distribution in the glove region. Determination of the final aerodynamic contour involved extensive analytical effort and wind tunnel testing of a 5-foot span JetStar model in the Calspan transonic wind tunnel ${ }^{14}$ (Fig. 10). A comparison of the analytically predicted surface pressures with Calspan experimentally measured data, including the effect of nacelles, shows good agreement (Fig. 9). The actual surface pressure gradient in the leading edge is not as steep as desired (Fig. 9) but is considered acceptable.

Advanced boundary-1ayer stability codes 17,18 were used to calculate the amplification rates ( $n$ factors) of the crossflow boundary-layer disturbances, which is the dominant disturbance mode in the leading-edge region. Aft of the front spar (beyond the region of applied suction) twodimensional Tollmien-Schlichting disturbances begin to amplify in addition to residual amplified crossflow disturbances. As aerodynamic contours were derived during the design process, the pressure distributions were input to the advanced stability codes to compute the amplification rates of the crossflow disturbances to ensure that (1) without suction, the boundary layer would be turbulent and, if so, that (2) with suction, the disturbance amplification could be maintained below some critical level. This critical level was established based on existing transition data.

A representative predicted upper surface pressure distribution, baseline suction level distribution, and crossflow disturbance amplification rate back to the front spar for a midspan location on the test article at the mid-cruise condition are illustrated in Figure 11 . With no suction applied, the crossflow disturbances will grow beyond the critical level causing boundary-layer transition on the test surface. With the baseline suction applied, the growth of the disturbances is held below the critical level. Calculations performed for numerous off-design conditions of Mach number $\mathrm{Cl}_{\mathrm{L}}$ and altitude indicate that either the baseline suction distribution or the planned over suction capability margin are sufficient to maintain laminar flow over a wide range of flight conditions, thus enhancing the research value of the flight test. In fact, off-design conditions may produce favorable pressure gradients to possibly extend laminar flow to $35 \%$ chord; thus, the filight test may provide limited data applicable to the hybrid laminar flow concept (HLFC).19 At these further aft chord locations where both crossflow and Tollmien Schlichting instabilities exist, it is suspected that the two disturbance modes couple 19 to cause transition earlier than would be predicted using the individual mode calculations. At present, virtually no data exist to establish design criteria for laminar flow wings either with or without disturbance mode coupling which illustrates one of the research benefits of the LEFT flight test program.

\section{LFC Systems and Aircraft Modification}

A schematic of the JetStar configured for the leading-edge flight test program is presented in Figure 8 . The heart of the suction system is the turbocompressor suction pump (Fig. 8) which is a modified AiResearch unit. Certain turbocompressor hardware and controls have been modified as required for application to this program. The turbocompressor is mounted in the unpressurized rear fuselage compartment of the Jetstar. As noted previously, to enhance the research value of these tests, to allow the control and measurement of key parameters, and to permit optimization of the systems, each of the 15 suction strips on the Douglas test article and each of the 27 slots on the Lockheed test article have individual flow adjustment control. Individual flow control is 
accomplished through the use of NASA designed chamber valves. One chamber valve handles the 15 Douglas suction lines and there is one chamber valve for the Lockheed upper surface lines and one chamber valve for the Lockheed lower surface lines. Each suction line has its own needle valve within the chamber valve which is designed to operate at sonic conditions. The chamber/needle valve assemblies were flow calibrated at NASA Langley. Measurement of total pressure ahead of the needle valve, needle position, and chamber valve pressure and temperature permits calculation of individual suction flow. A few selected lines will also have direct reading mass flow transducers for comparison with the calculated flow rates.

A purge flow system is provided for utilization by both contractors to remove any residual or trapped PGME fluid, water, or other contaminants from the suction lines, flutes, and suction surface. There are actually two purge systems, the primary purge system and the secondary purge system. Air for the secondary purge system is provided by diverting flow from the normal aircraft air conditioning system and is available from ground up to 12,000 feet altitude. Above 12,000 feet, the primary purge system provides flow from the jetStar emergency pressurization system. Use of the primary purge system is prohibited below 12,000 feet because the air is too high in temperature and may damage the LFC systems. The purge flow connects into the main suction ducting with appropriate control valves and thus passes through the chamber valves in route to the test articles.

A high pressure $(3,200$ psi tank) nitrogen system is provided to serve four basic functions: (1) pressurize the PGME cleaning/anti-icing fluid tanks, (2) purge PGME fluid from the Douglas spray nozzles and supply line, (3) operate several purge valves, and (4) purge ail pressure instrumentation lines of residual fluids and contaminants. Numerous pressure regulators and control valves in the nitrogen system allow delivery of the required pressures throughout the system.

\section{Instrumentation, Displays, Data Acquisition}

Instrumentation has been provided for measurement of parameters on the flight test articles and fairings surfaces, internal flow passages, and in key areas throughout the laminar flow and supporting systems (Fig. 12). This instrumentation will permit monitoring and control of flight conditions, surface pressures, suction distributions, and state of the boundary layer (laminar-transitionalturbulent). System conditions (pressure, temperature, control valve positions, etc.) will be measured and monitored throughout the aircraft.

An array of surface pitot tubes is positioned spanwise along the front spar (Fig. 12) on a removable sensor panel to detect the condition of the boundary layer and, in the event local regions of turbulent flow occur, the closely spaced pitots can pinpoint the origin of the disturbance. A total of 12 hot films on each test surface are located at one spanwise location, with six hot films on the test article, one on the sensor panel, and five on the aft panel back to about $35 \%$ chord. These aft hot films were installed because at certain off design conditions, laminar flow may exist somewhat behind the front spar (with the pitot tube array removed and care taken to smooth joints and fasteners) and thus provide additional data for development of transition prediction methods for design of laminar flow wings. The pitot and hot film data will be displayed and monitored on each contractor's CRT frequently during flight testing.

A commercially available laser particle spectrometer (Knollenberg probe) will be installed on a pylon on the fuselage upper surface to measure cloud ice particles encountered in flight (Fig. 13). It is known 7,8 from previous laminar flow flight experiments that laminar flow can be lost when encountering cirrus clouds at cruise conditions, however only qualitative ice crystal data were obtained. The Knollenberg probe will permit quantitative measurement of ice particles in 30 size categories from 20 to 600 micrometers in diameter (Fig. 14) so that criteria for possible laminar flow loss due to particle encounters can be established. A description of the Knollenberg probe operation, measuring and testing techniques, and data analys is methods for the LEFT program is given in Reference 20. A charge plate cloud particle detector developed at Langley will be mounted on the leading edge of the pylon on the fuselage upper surface (Fig. 13). This unit functions on the principle that aircraft surfaces develop a charge when ice or water droplets strike the surface. A device operating on the same principle was utilized in earlier LFC flights 7,8 and detected the presence of clouds and subsequent laminar flow loss. The purpose of developing and evaluating this device is to provide a low-cost unit for detecting ice particles and pending laminar flow loss which could be applied to future laminar flow aircraft. 20

Each test article will have its own control console (Fig. 8) containing a minicomputer (32K), a CRT for display of key parameters in real time, and the control functions allowing setting of suction distributions and activation of other systems. Onboard computing capability and software will allow calculation of needed parameters from measured variables for display and hard copy printing in real time. The NASA DFRC JetStar aircraft utilizes a pulse code modulating (PCM) data acquisition system. All measured data will be recorded on an analog tape for later reduction and analysis. A telemetry transmitter will send key data to the ground control room for display and monitoring on 2 CRT's, $2 x-y$ plotters, and several strip charts. A third console on the JetStar configured for this flight program contains a third minicomputer and display, and serves as an interface between the raw data and the two contractor consoles, converting the basic counts to engineering units.

A separate consolette will be attached to the console monitoring the Douglas test article and systems. This consolette will contain the control and monitoring functions for those systems which are common to both test articles; i.e., operation of the turbocompressor (and thus the suction system), operation of the nitrogen system, and operation of the purge systems. The consolette will be within arms length of the individual operating the Lockheed console so that either test article can be flight tested independent of the other.

Controls will be installed giving the pilot sole control over deployment and retraction of the OAC Krueger shield and arming/disarming of the turbocompressor. 
Flight Test Plans

Ground and Flight Acceptance Testing. Following installation of the test articles and all LFC systems and support systems, a functional ground checkout will be performed to establish readiness of all systems. A ground vibration test will be conducted to determine the structural modal response characteristics of the modified JetStar and to validate the vibration analysis performed by Lockheed, thus confirming the structural integrity of the aircraft prior to the first flight. The first flight of the aircraft will be a flutter clearance flight to establish the flutter boundaries of the modified JetStar (with the Douglas Krueger shield retracted and deployed) and to ensure the JetStar will be flutter-free within the expected flight testing envelope. Flight acceptance tests will be performed to establish and verify that all systems operate and perform as designed and to gain sufficient experience in their operating characteristics to permit more extensive research flight performance and evaluation testing to begin.

Systems Performance and Evaluation Flight Testing. The objective of this phase of the flight test program is to thoroughly exploit the LFC systems and supporting subsystems operation permitting a complete evaluation of their performance for design and off-design conditions. The bulk of this testing will be performed at DFRF, with possible excursions to major California airports to obtain data on the performance of the insect protection/ cleaning system. One of the first thrusts of this flight testing effort will be to ensure that at the design conditions of $M=0.75$ and 38,000 feet, the boundary-layer flow is turbulent without suction and laminar with the baseline suction. Surface pressure distributions for all design and off-design conditions will be measured and recorded, and, if required, the boundary-layer stability codes will be used to determine a revised baseline suction distribution.

The suction system performance will be demonstrated and evaluated initially at the design condition, maintaining the baseline suction level and observing the effect of cruise $C_{L}$ changes 10.38 to 0.26$)$. Additional flights at design conditions will explore the effect of raising or lowering the suction levels (maintaining the same distribution) while still other flights will involve varying the suction distribution shape and exploring minimum and near optimum suction levels which can support laminar flow. Off-design flights will be conducted to vary Mach number, altitude, Reynolds number, $C_{L}$, and suction distributions to acquire a data base for later analyses of laminar flow sensitivity to these parameters.

For later flights, the pitot array at the front spar (for sensing the condition of the boundary layer) will be removed and the joints and fastener holes filled and smoothed behind the front spar. Flight conditions will be established that provide a range of favorable and adverse pressure distributions past the front spar to determine if laminar flow can be sustained over the sensor panel and a portion of the rear aerodynamic fairing (to about $30-40 \%$ chord). Pressure distributions back to about $60 \%$ chord and hot-film boundary-layer condition measurements back to about $35 \%$ chord will be obtained. These data would provide limited additional insight on the feasibility and application of hybrid laminar flow concepts.

At some point early in the systems performance and evaluation flight testing, the insect protection/cleaning system performance must be evaluated so that it can be utilized to protect the leading edge as required. Initial system operation will utilize water instead of PGME, and dyes, visual observations, and video equipment will be used to record surface coverage. Low flow rates to avoid saturation of the structure will be employed at first, and measurement of cleaning fluid used will be a key indicator in attempts to optimize the system.

Evaluation of the anti-icing system may be difficult to perform on a planned schedule due to the limited encounter of icing conditions. If an icing condition is encountered, the original flight plan may be modified to gain experience with the antiicing system. Complete performance evaluation of this system may await the simulated airline service flight testing in the northern part of the United States during the winter months.

Data will be obtained continuously on all laminar flow flights with the knollenberg probe to document ice particle encounters in cloud and haze conditions, and correlate the degree of laminar flow loss with ice particle concentrations. The voice record of the flight crew describing the degree of cloud cover, cloud type, and visibility will be utilized in interpreting the Knollenberg probe data.

Simulated Airline Service Testing. The primary objective of the leading-edge flight test program is to demonstrate the effectiveness of the leading-edge systems in maintaining laminar flow under representative flight conditions. The culmination of this objective is to operate the Jetstar in a simulated airline service to obtain the day-to-day operational experience, establish a maintenance and reliability data base, and determine the operational sensitivity of the laminar flow systems.

The plan for this series of testing is to operate out of designated "home base" areas throughout the United States (Fig. 15). Operation of the laminar flow systems and subsystems will rely heavily on the experience accrued in the earlier phases of flight testing. The modified JetStar will operate for approximately a 2-week period at each of at least four home base major commercial airport areas. Two or more flights will be conducted daily, with each consisting of takeoff, climb to cruise altitude, achievement of laminar flow for some minimum period, descent, landing, and inspection of the test articles. The condition of the test articles (possible insect remains, clogged or contaminated suction surfaces, etc.) will be fully documented after each flight. Special measures to clean or otherwise maintain the test article surfaces or systems will be minimal in order to establish a maintenance and reliability data base. The suction levels utilized will be those considered optimum based on results from the system evaluation and performance flight testing, and will not be readjusted in cruise. Full instrumentation will remain on the aircraft for monitoring boundary layer and surface conditions, all system parameters, and ice particle concentrations. 
Following each 2-week concentrated simulated airline service flight testing, there will be approximately a 4-week interval at DFRF for regularly scheduled JetStar maintenance, analyses of the flight test results, and preparation for the next series of flight testing. The results from the simulated airline service flight testing should be a major step in demonstrating to industry the technology readiness of laminar flow systems for application to commercial transports.

\section{Concluding Remarks}

Results from the leading-edge flight test will allow the evaluation of two concepts for the leading-edge systems that might be required for a future LFC commercial transport. The simulated airline service flight program will provide day-to-day operational experience to establish the reliability of the systems, and an assessment will be made of the maintenance requirements to achieve this reliability. These data should demonstrate the practicality of the leading-edge concepts and resolve the major concerns of industry for the leading-edge problems of a future LFC transport.

\section{References}

1. Tollmien, W.: Über die Entstehung der Turbulenz. Mitteilung, Nachr. Wiss. Göttingen, Math. Phys. Klasse 21-44 (1929); Engl. transl. in NACA TM No. 609 (1931).

2. Schlichting, H.: Zur Enstehung der Turbulenz bei der Plattenströmung. Nachr. Ges. Wiss. Göttingen, Math. Phys. Klasse 182-208 (1933); see also Zamm 13, $171(1933)$.

3. Schubauer, G. B.; and Skramstad, H. K.: Laminar Boundary Layer Oscillations and Stability of Laminar Flow. National Bureau of Standards Research Paper 1772 (Reprint of a classified NACA Report first published in April 1943, and later released as NACA Wartime Report $W-8\rangle$, and J. Aero. Sci. 14, 69 (1947); see also NACA Rep. No. 909.

4. Groth, E. E.; Carmichael, B. H.; Whites, R. C.; and Pfenninger, W.: Low Drag Boundary Layer Suction Experiments in Flight on the Wing Glove of a F94-A Airplane-Phase II: Suction Through 69 Slots. NAI $-57-318$, BLC-94 (Contract AF-33(616)-3168), Northrop Aircraft, Inc., Feb. 1957.

5. Antonatos, P. P.: Laminar Flow Control Concepts and Applications. Astronautics and Aeronautics, July 1966.

6. Nenni, J. P.; and Gluyas, G. L.: Aerodynamic Design and Analysis on an LFC Surface. Astronautics and Aeronautics, July 1966.

7. White, R. C.; Sudderth, R. W.; and Wheldan, W. G.: Laminar Flow Control on the $X-21$. Astronautics and Aeronautics, July 1966.

8. Pfenninger, W.; and Reed, V. D.: Laminar-Flow Research and Experiments. Astronautics and Aeronautics, July 1966.
9. Povinelli, F. P.; Klineberg, J. M.; and Kramer, J. J.: Improving Aircraft Energy Efficiency, Astronautics and Aeronautics (AIAA), Vol. 14, No. 2, Feb. 1976.

10. Wagner, R. D.; and Fischer, M. C.: Developments in the NASA Transport Aircraft Laminar Flow Program. AIAA Paper No. 83-0090, January 1983.

11. Sturgeon, R. F.; et al.: Evaluation of Laminar Flow Control System Concepts for Subsonic Commercial Transport Aircraft. NASA CR-159253, September 1980.

12. Anon.: Evaluation of Laminar Flow Control Systems Concepts for Subsonic Commercial Transport Aircraft. NASA CR 159251, June 1983.

13. Peterson, J. B., Jr.; and Fisher, D. F.: Flight Investigation of Insect Contamination and Its Alleviation. NASA CP 2036, Part I, Feb.-Mar. 1978, pp. 357-373.

14. Anon.: Laminar Flow Control Leading Edge Glove Flight-Aircraft Modification Design, Test Article Development and Systems Integration. NASA CR 172136, 1983.

15. Anon.: Laminar Flow Control Leading Edge Glove Flight Test Article Development. NASA CR-172137, 1983.

16. Pearce, W. E.: Progress at Douglas on Laminar Flow Control Applied to Commercial Transport Aircraft. Presented to the 13th Congress of the ICAS/AIAA Aircraft Systems and Technology Conference, August 1982.

17. Srokowski, A. J.; and Orszag, S. A.: Mass Flow Requirements for LFC Wing Design. AIAA Paper No. 77-1222, August 1977.

18. Dagenhart, J. R.: Amplified Crossflow Disturbances in the Laminar Boundary Layer on Swept Wings With Suction. NASA TP 1902, Nov. 1981.

19. Anon.: Hybrid Laminar Flow Control Study. NASA CR 165930, Oct. 1982.

20. Davis, R. E.; and Fischer, M. C.: Cloud Particle Instrumentation for the Laminar Flow Control Leading Edge Flight Test. AIAA Paper No. 83-2734, November 1983. 


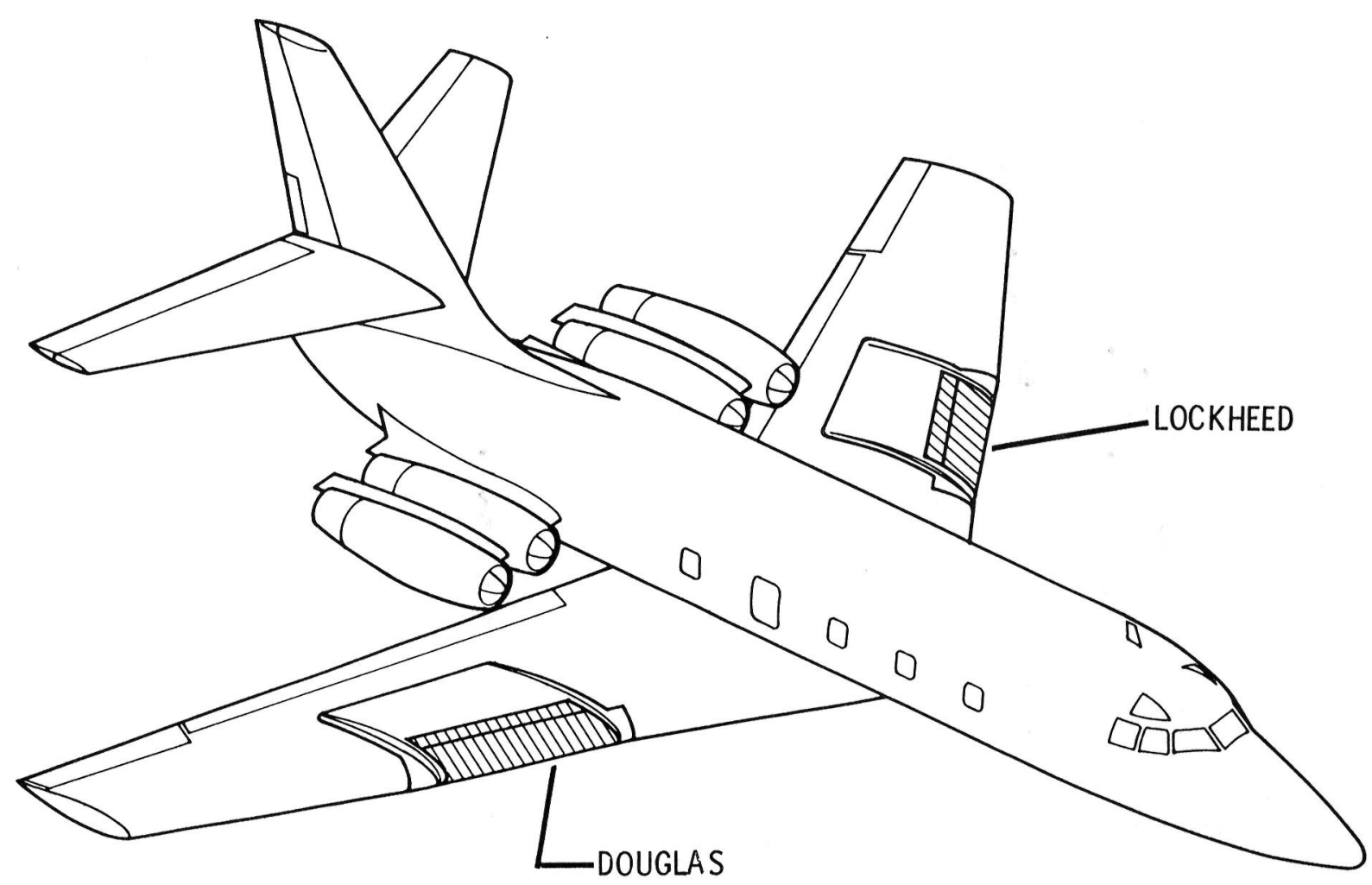

FIGURE 1 - TEST ARTICLE INSTALLATION ON THE DFRF JETSTAR

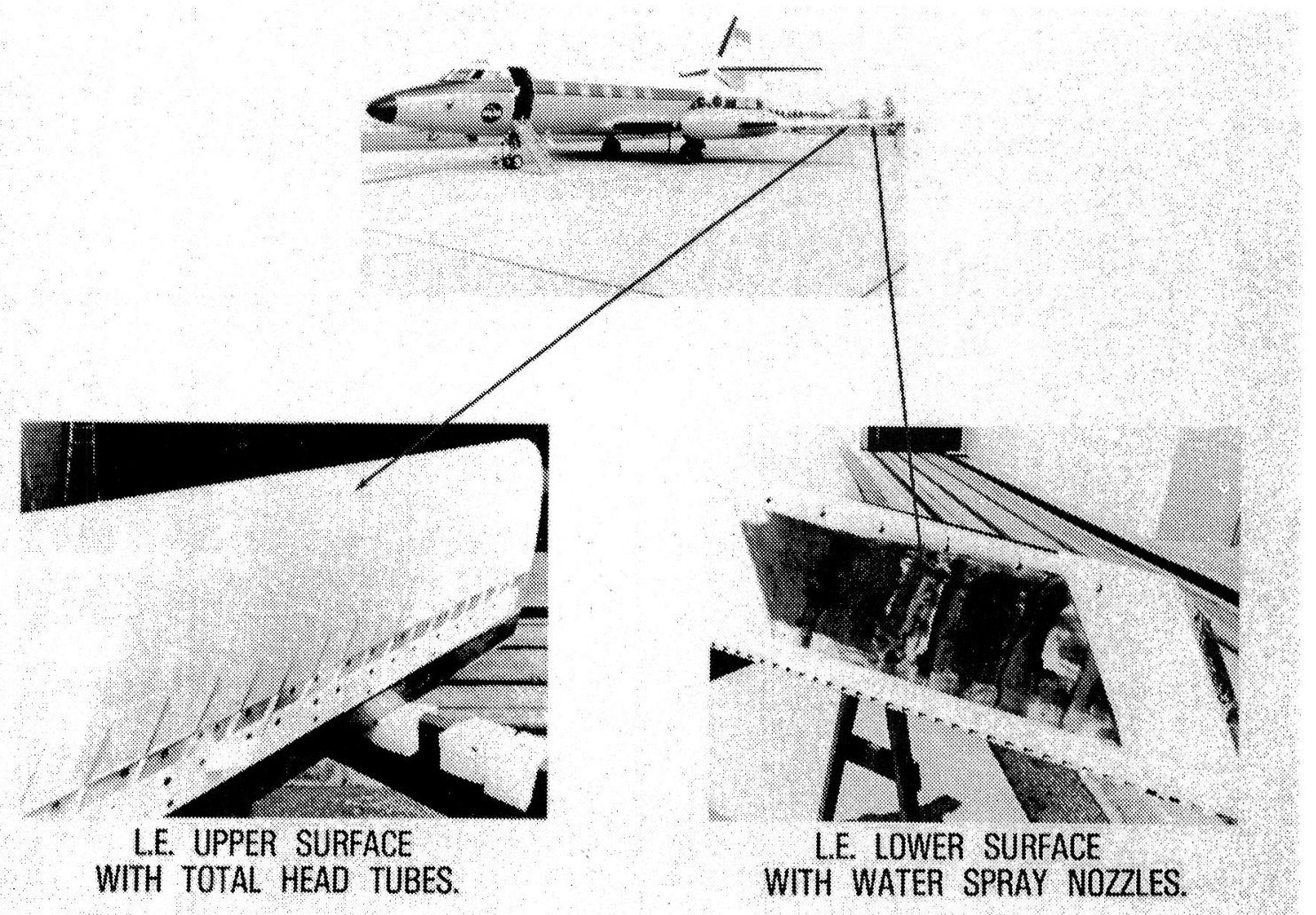

FIGURE 2 - LEADING EDGE CONTAMINATION FLIGHT TEST 


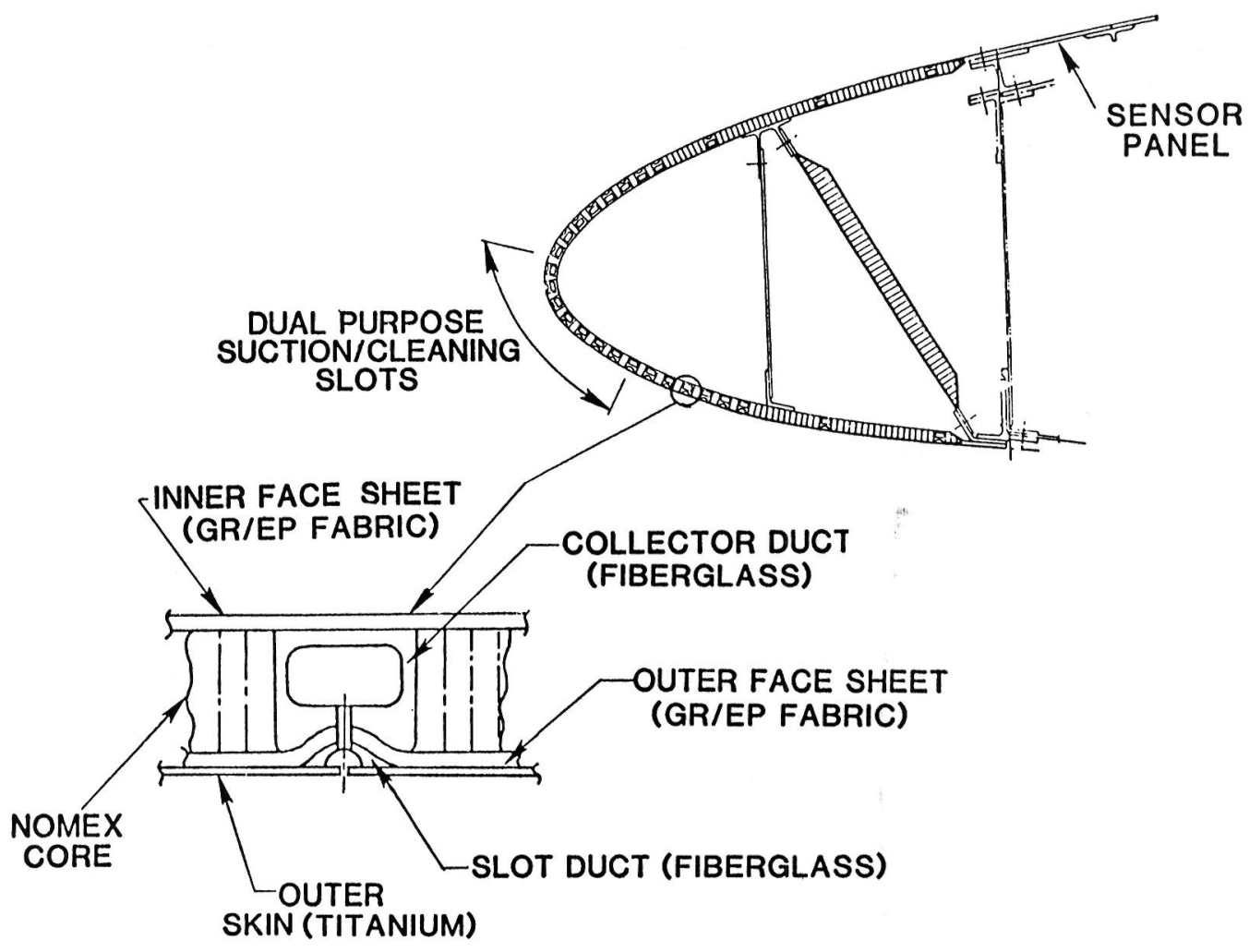

FIGURE 3 - LOCKHEED FLIGHT TEST ARTICLE

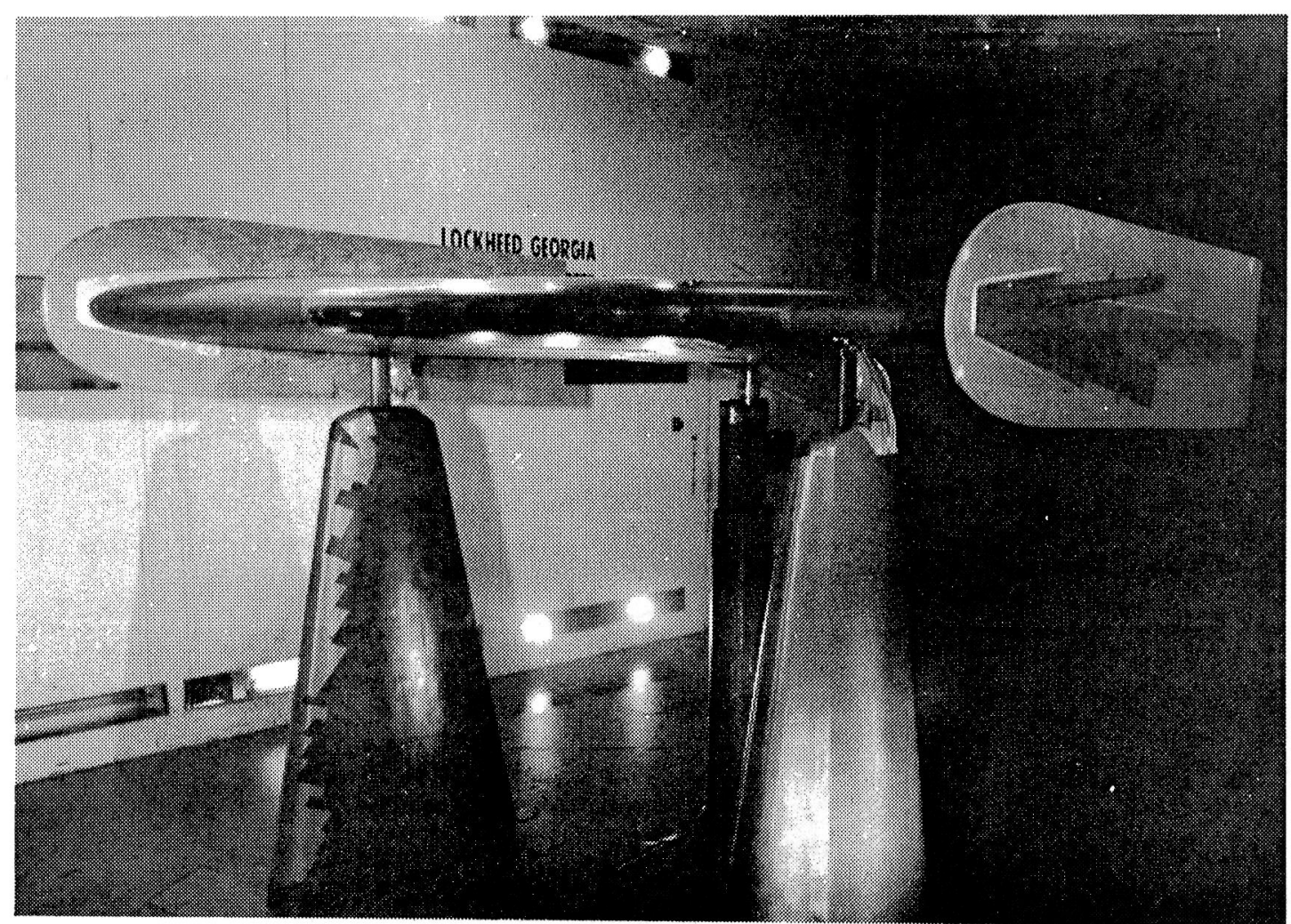

FIGURE 4 - LOCKHEED LEADING EDGE WIND TUNNEL TEST 

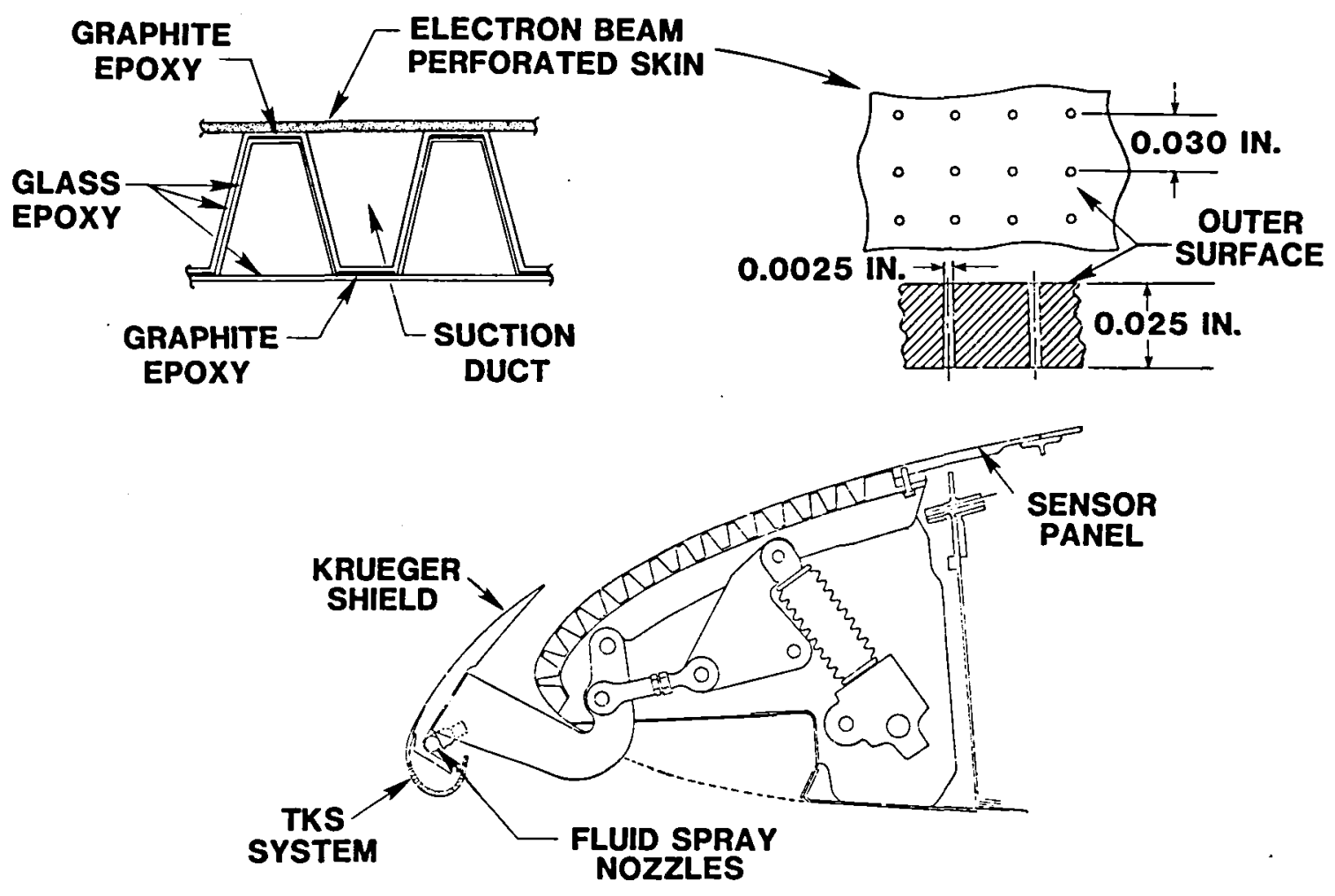

FIGURE 5 - DOUGLAS FLIGHT TEST ARTICLE

\section{TRAJECTORY \\ ANALYSIS}

OUTBOARD (TIP)

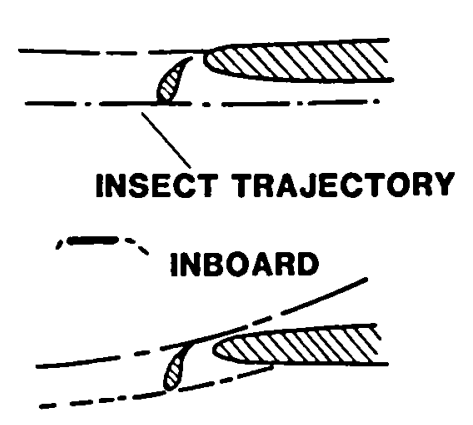

STUDY PARAMETERS

- AIRSPEED

- ANGLE Of ATTACK

- FLAP SETTING

- SPAN STATION

- INSECT MASS/DRAG

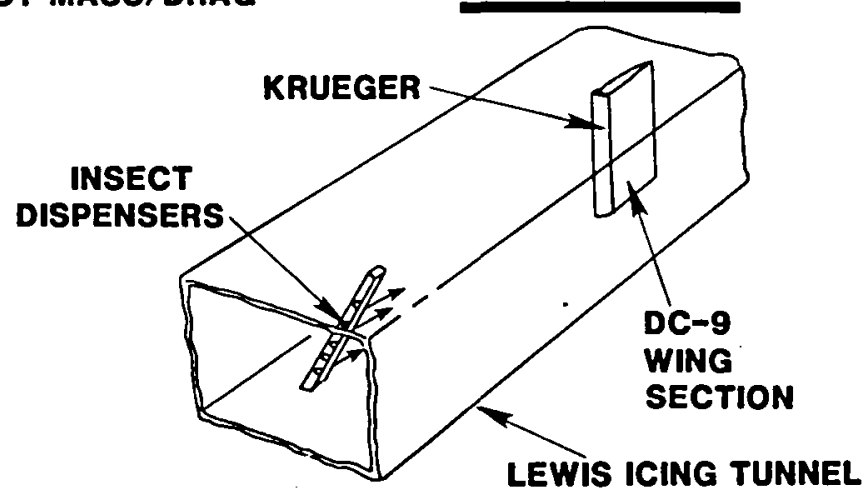

FIGURE 6 - DOUGLAS KRUEGER INSECT SHIELD TRAJECTORY ANALYSIS AND WIND TUNNEL TEST 


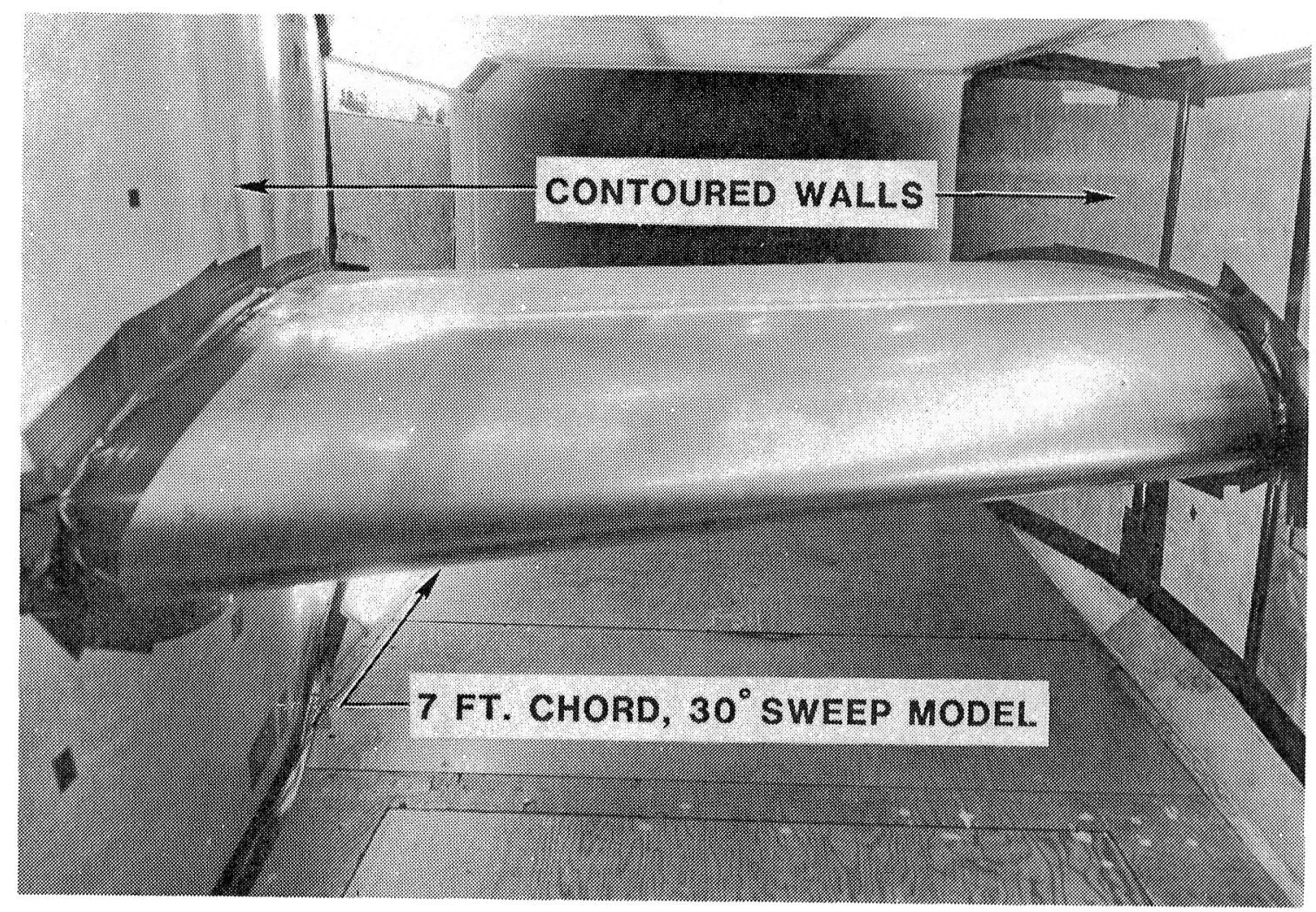

FIGURE 7 - DOUGLAS LEADING EDGE WIND TUNNEL TEST

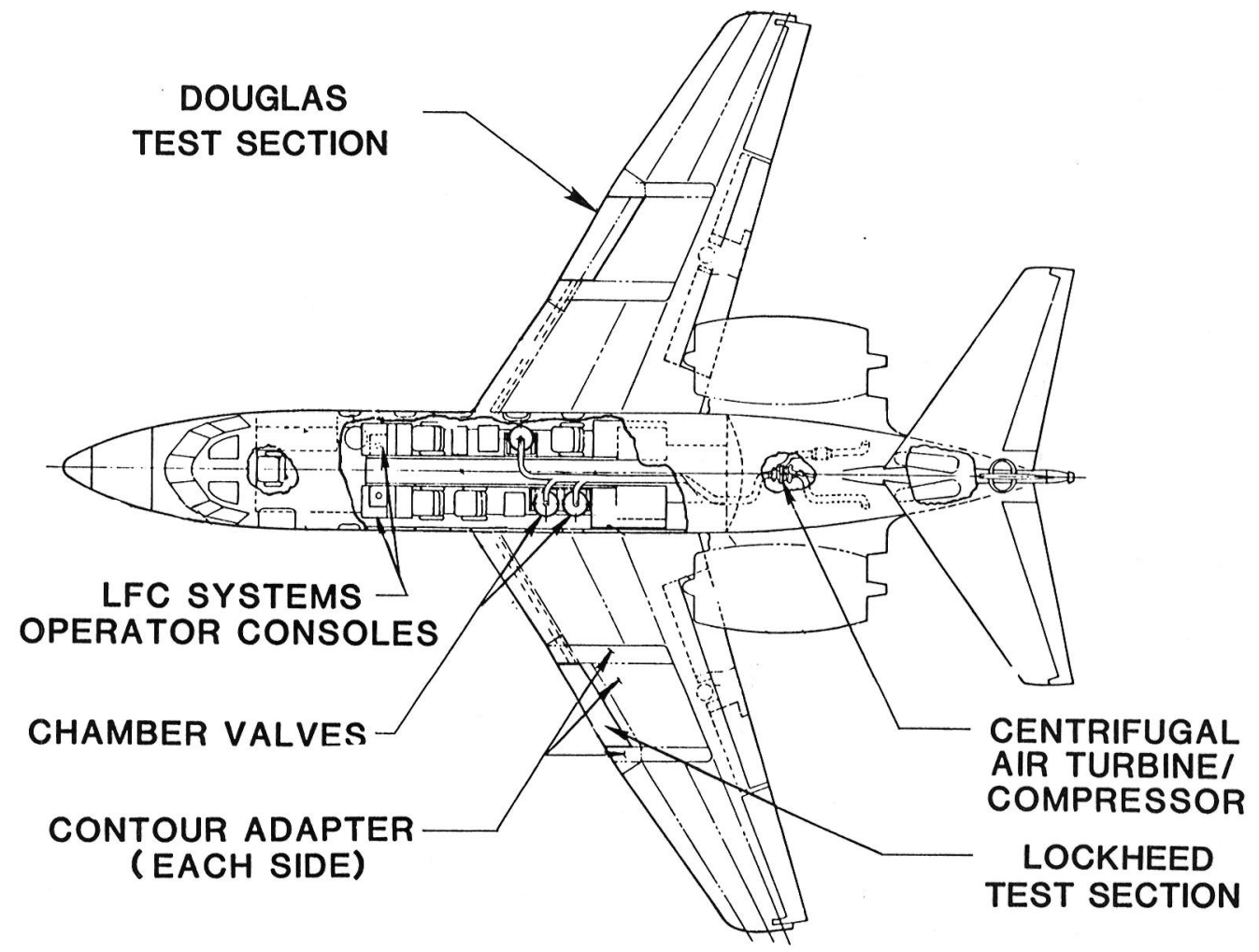

FIGURE 8 - LEFT SYSTEMS INSTALLATION AND MODIFICATION ON THE JETSTAR 


\section{DESIGN GOALS}

REPRESENTATIVE $C_{p}$, LOCAL M, SUCTION LEVELS

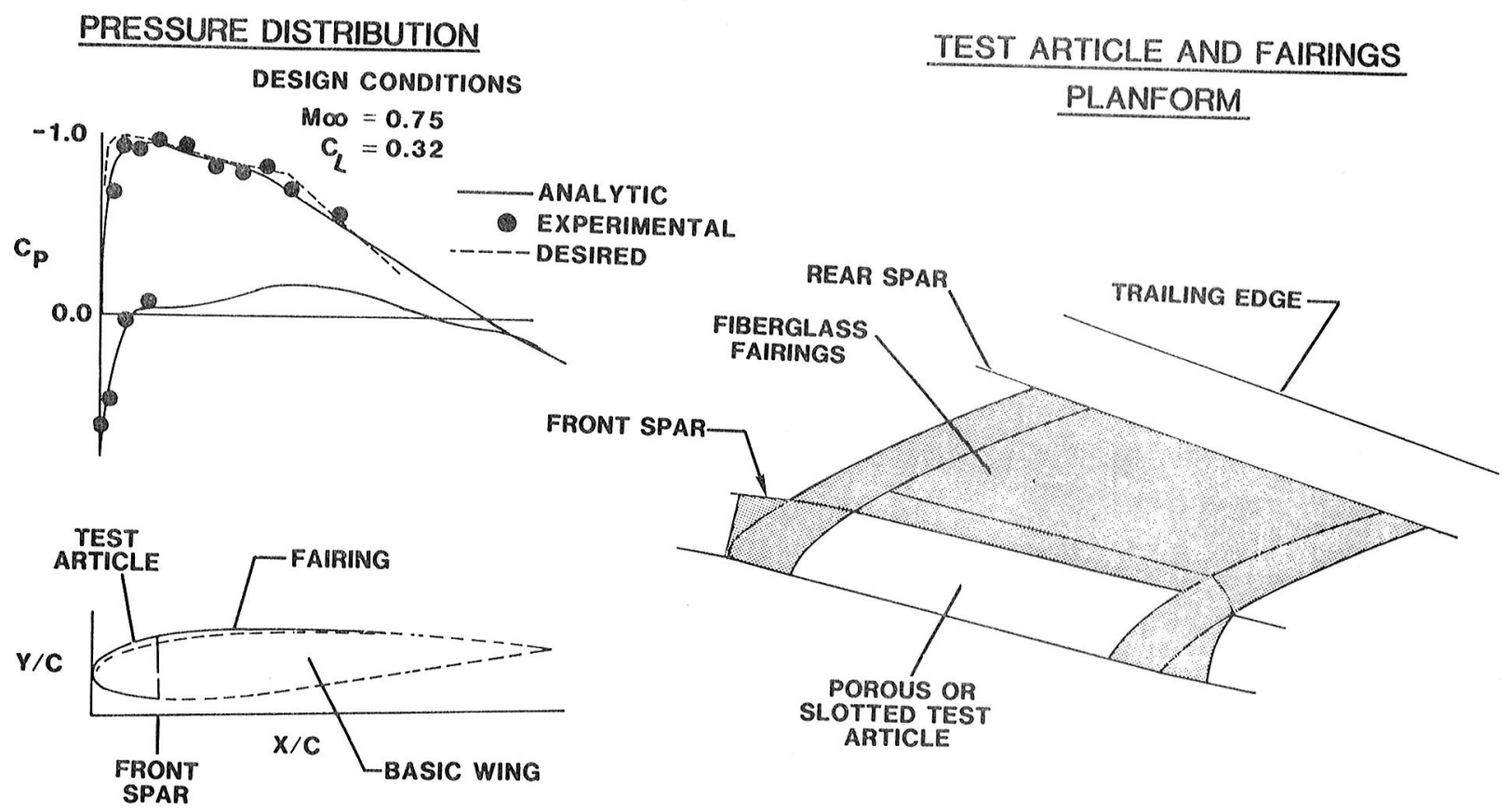

FIGURE 9 - LEFT AERODYNAMIC CONTOUR DESIGN

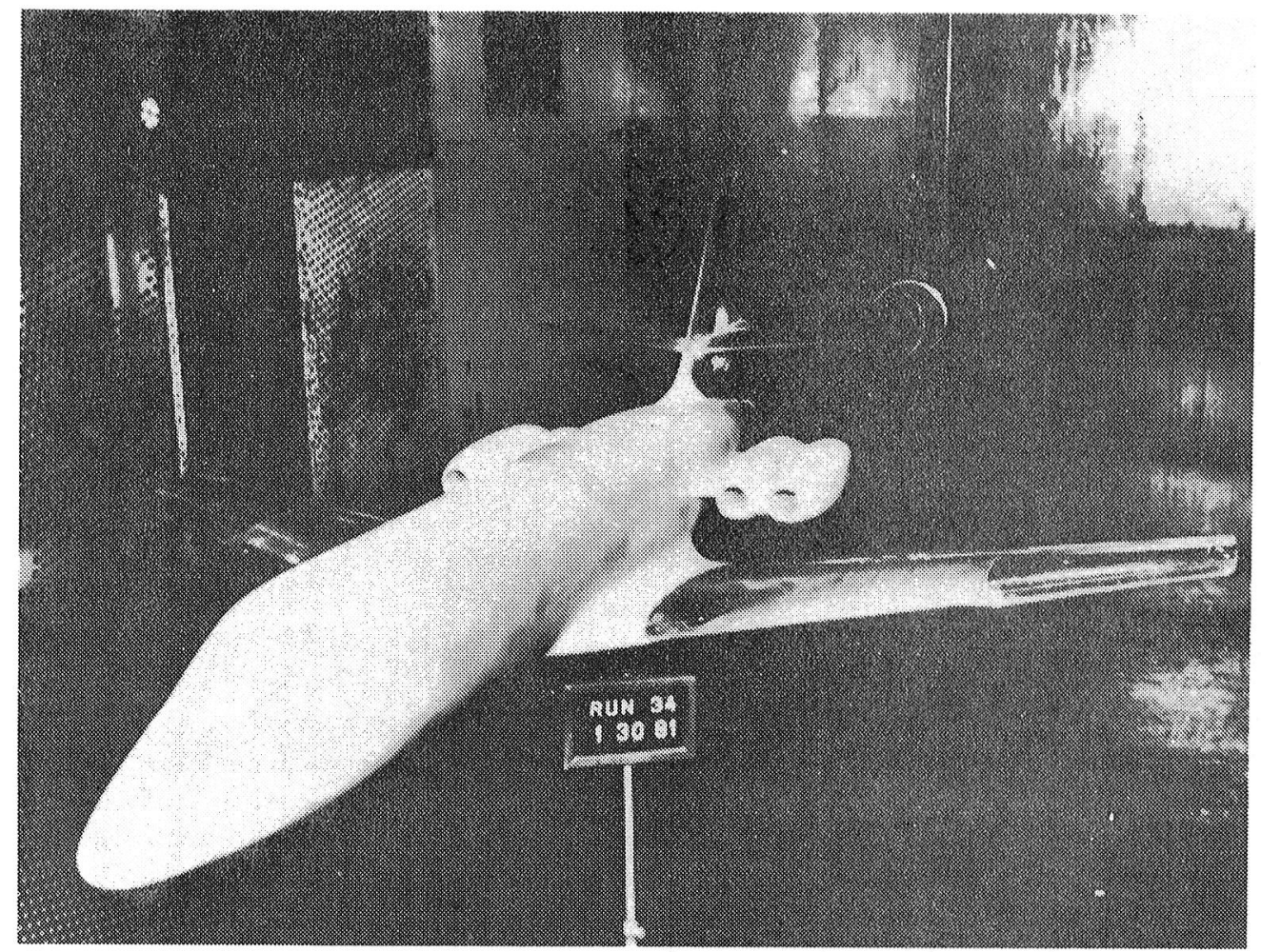

FIGURE 10 - JETSTAR WIND TUNNEL MODEL INSTALLED IN THE CALSPAN TRANSONIC TUNNEL 

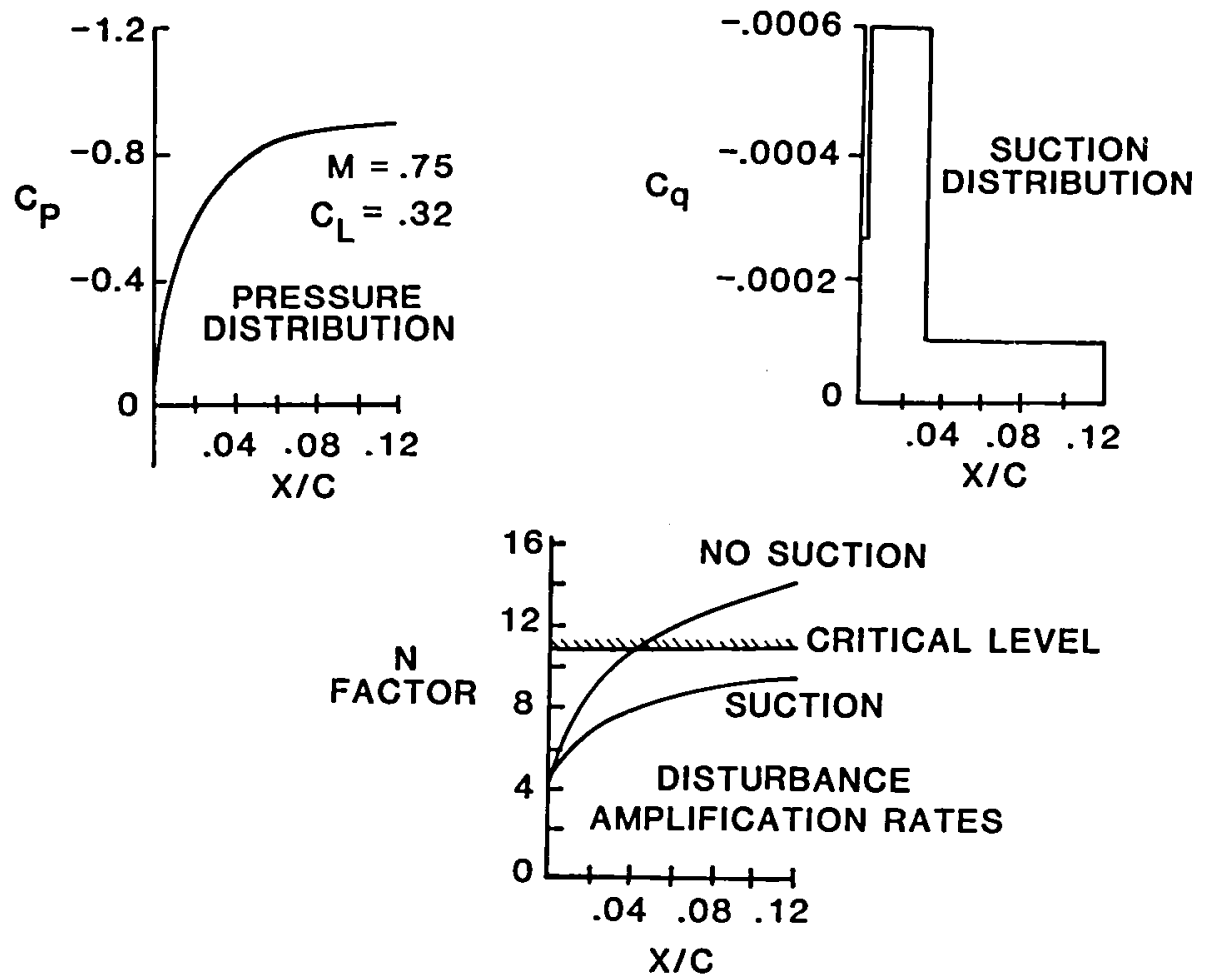

FIGURE 11 - SUCTION REQUIREMENTS FOR THE LEADING EDGE TEST ARTICLE

\section{ARTICLE AND FAIRING}

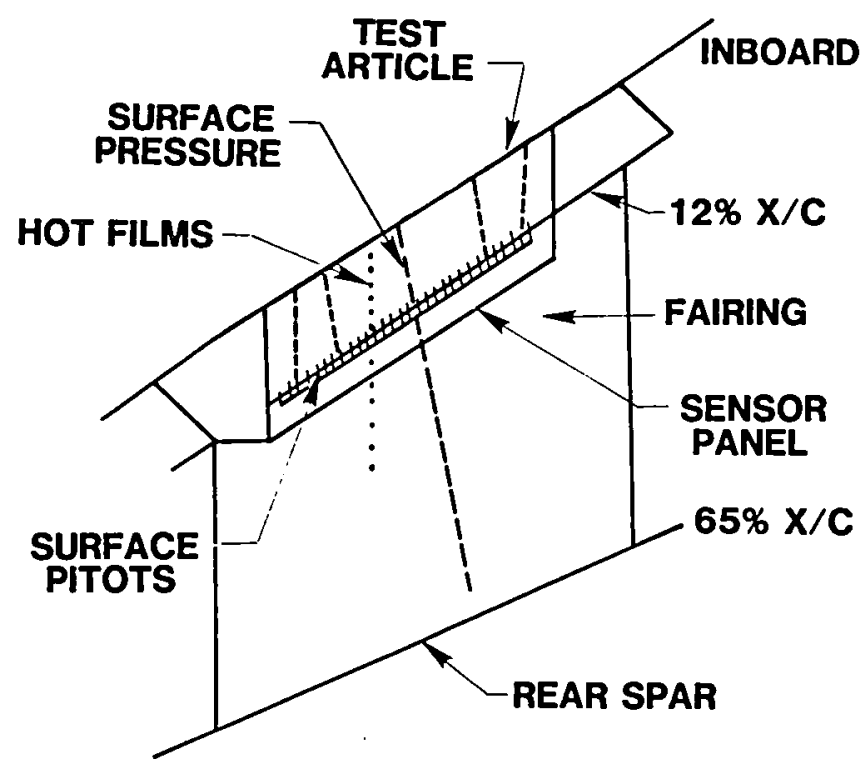

MEASUREMENTS \& CRT DISPLAYS

- A/C \& FLIGHT PARAMETERS

- DUCT, LINE PRESSURES \& TEMPERATURES

- MASS FLOWS, SUCTION DISTRIBUTIONS

- ice particle fluX, a/C charge

- CLEANING / ANTI-ICING FLUID fLOW RATES AND PRESSURE

- VALVe POSITIONS AND PRESSURES

- TURBOCOMPRESSOR SYSTEM PARAMETERS

- BOUNDARY LAYER MONITORING

-HOT FILMS

-PITOTS

- SURFACE PRESSURE DISTRIBUTIONS 


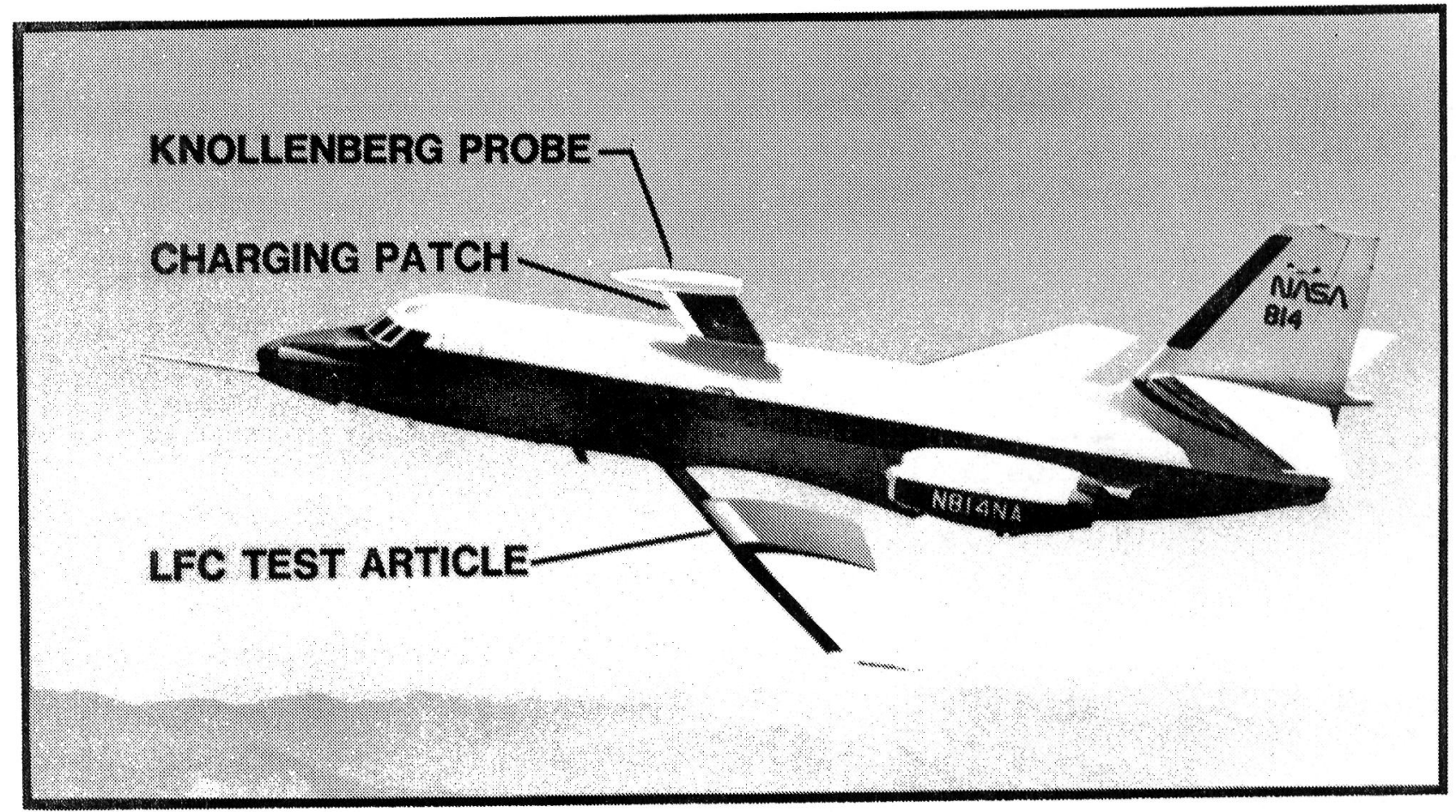

FiguRE 13 - INSTALLATION OF KNOLLENBERG PROBE AND CHARGE PLATE ON JETSTAR
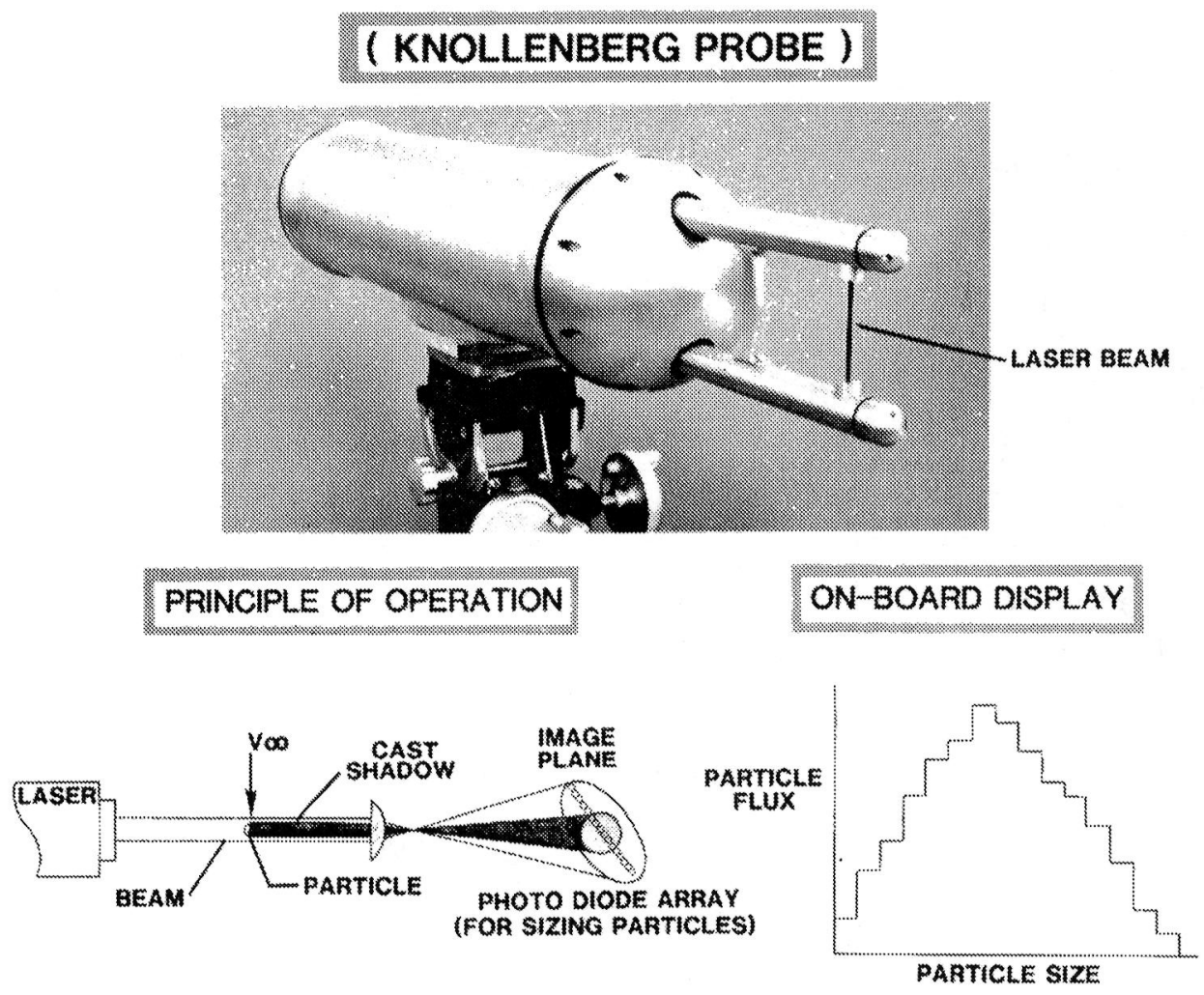

FIGURE 14 - KNOLLENBERG PROBE (OPTICAL ARRAY SPECTROMETER) 


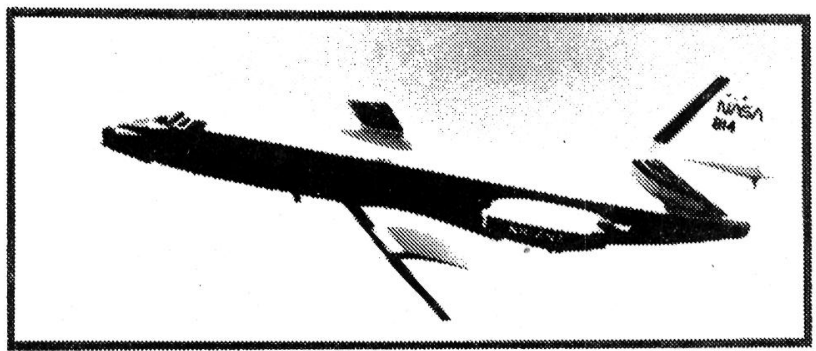

SIMULATED AIRLINE SERVICE HOME BASES

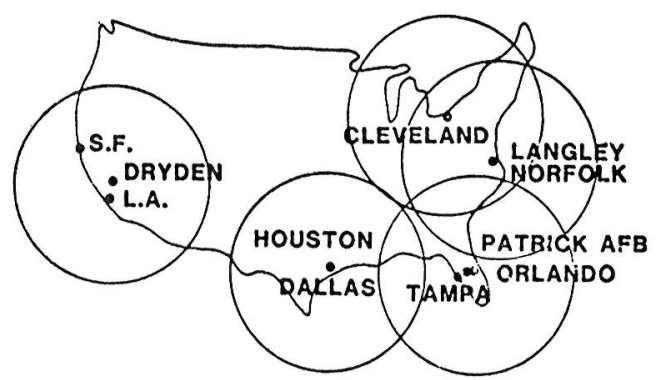

- OPERATE OUT OF HOME BASES ACROSS THE UNITED STATES

- CONDUCT TWO OR MORE FLIGHTS DAILY IN HANDS OFF MODE

- OBTAIN DATA ON OPERATIONAL SENSITIVITIES, MAINTAINABILITY, RELIABILITY IN DAY-TO-DAY SERVICE

- DETERMINE INFLUENCE OF ENVIRONMENT , i.e., TEMPERATURE, HUMIDITY, CLOUDS, INSECTS, RAIN, SNOW, ICE, CONTAMINANTS

FIGURE 15 - SIMULATED AIRLINE SERVICE FLIGHT TESTS 


\begin{tabular}{|c|c|}
\hline $\begin{array}{l}\text { 1. Report No. } \\
\text { NASA TM-85712 }\end{array}$ & 3. Recipient's Catalog No. \\
\hline \multirow[t]{2}{*}{$\begin{array}{l}\text { 4. Title and Subtitle } \\
\text { A Flight Test of Laminar Flow Control Leading-Edge Systems }\end{array}$} & $\begin{array}{l}\text { 5. Report Date } \\
\text { December } 1983\end{array}$ \\
\hline & $\begin{array}{l}\text { 6. Performing Organization Code } \\
505-45-63\end{array}$ \\
\hline $\begin{array}{l}\text { Michaef(s) C. Fischer, Andrew S. Wright, Jr., and } \\
\text { Richard D. Wagner }\end{array}$ & 8. Performing Organization Report No. \\
\hline \multirow{3}{*}{$\begin{array}{l}\text { 9. Performing Organization Name and Address } \\
\text { NASA Langley Research Center } \\
\text { Hampton, Virginia } 23665\end{array}$} & 10. Work Unir No. \\
\hline & 11. Contract or Grant No. \\
\hline & 13. Type of Report and Period Covered \\
\hline \multirow{2}{*}{$\begin{array}{l}\text { 12. Sponsoring Agency Name and Address } \\
\text { Nationa] Aeronautics and Space Administration } \\
\text { Washington, DC } 20546\end{array}$} & Technical Memorandum \\
\hline & 14. Sponsoring Agency Code \\
\hline \multicolumn{2}{|c|}{$\begin{array}{l}\text { 15. Supplementary Notes Presented at: } \\
\text { AIAA Aircraft Design, Systems and Operations Meeting } \\
\text { Fort Worth, Texas } \\
\text { October 17-19, 1983 }\end{array}$} \\
\hline
\end{tabular}

16. Abstract

NASA's Program for development of a laminar flow technology base for application to commercial transports has made significant progress since its inception in 1976. Current efforts are focused on development of practical reliable systems for the leading-edge region where the most difficult problems in applying laminar flow exist. Practical solutions to these problems will remove many concerns about the ultimate practicality of laminar flow. To address these issues, two contractors performed studies, conducted development tests, and designed and fabricated fully functional leading-edge test articles for installation on the NASA JetStar aircraft. Systems evaluation and performance testing will be conducted to thoroughly evaluate all system capabilities and characteristics. A simulated airline service flight test program will be performed to obtain the operational sensitivity, maintenance, and reliability data needed to establish that practical solutions exist for the difficult leading-edge area of a future commercial transport employing laminar flow control.

\begin{tabular}{|c|c|c|c|c|}
\hline \multicolumn{2}{|c|}{$\begin{array}{l}\text { 17. Key Words (Suggested by Author(s)) } \\
\text { Laminar Flow, Flight Testing, } \\
\text { Fuel Efficiency, Transport Aircraft, } \\
\text { Composite Structure }\end{array}$} & \multicolumn{3}{|c|}{$\begin{array}{l}\text { 18. Distribution Statement } \\
\text { Unclassified - Unlimited } \\
\text { Subject Category } 01\end{array}$} \\
\hline $\begin{array}{l}\text { 19. Security Classif. (of this report) } \\
\text { Unclassified }\end{array}$ & $\begin{array}{l}\text { 20. Security Classif. (o } \\
\text { Unclass ified }\end{array}$ & & $\begin{array}{l}\text { 21. No. of Pages } \\
16\end{array}$ & $\begin{array}{l}\text { 22. Price } \\
\mathrm{AO2}\end{array}$ \\
\hline
\end{tabular}


